\title{
The Effect of Different Fertilizer and Extraction Method on Secondary Metabolites of Azolla Pinnata
}

\author{
Muhammad Ameerul Haqim Roshidia, Husna Sabrina Mahyuddina, Mohd Azrul Naim Mohamad, \& Abdul \\ Latif Noha* \\ a Department of Plant Science, Kulliyyah of Science, International Islamic University Malaysia, Jalan Sultan Ahmad Shah, Bandar Indera Mahkota, 25200 \\ Kuantan, Pahang, Malaysia \\ b Department of Biotechnology, Kulliyyah of Science, International Islamic University Malaysia, Jalan Sultan Ahmad Shah, Bandar Indera Mahkota, 25200 \\ Kuantan, Pahang, Malaysia \\ *Corresponding author e-mail: latifnoh@iium.edu.my
}

\section{DOI: 10.2478/acmy-2020-0005}

\begin{abstract}
:
Azolla pinnata is an aquatic plant that comes from the order of Pteridophyta and family of Azollaceae that can be found floating on the surface of waters and can only grow at non-moving or slow-moving water areas. This research aims to understand the effect of different extraction methods and fertilizers on Azolla pinnata and its secondary metabolites. The fertilizers treatments that were tested were chicken manure and AB. The different extraction methods that were tested were SFE and Soxhlet extraction. In the test, the amount of dry weight of A.pinnata obtained from using AB fertilizer was higher compared to chicken manure. For the extraction, both SFE and Soxhlet extraction produced an almost similar amount of extracts but different amounts of secondary metabolites. The amounts of the secondary metabolites were determined and analyzed using GC-MS. The metabolites identified were theamine, bioxirane, acetic acid, 9 methyl-1-decene, glycerine, dihydroxyacetone, thymine, pyranone, 6-fluoro-2-trifluoromethylbenzoic acid, 2-formyl-4,6 dichlorophenyl ester, and isoglutamine. Based on the result, treatment with $\mathrm{AB}$ fertilizer provides higher amounts of secondary metabolites in A.pin nata compared to chicken manure, while for extraction methods, SFE provides higher amounts of secondary metabolites in A.pinnata compared to Soxhlet extraction.
\end{abstract}

Keywords: Pteridophyta, Azolla pinnata, fertilizers treatments, theamine, bioxirane

\subsection{Introduction:}

Plants generate various types of compounds to ensure their survivability. One of the important compounds is the secondary metabolite, and these compounds are not directly involved in the normal growth, development, and reproduction of plants. Unlike primary metabolites, the absence of secondary metabolites does not result in immediate death but rather a long term impairment or maybe no significant change at all. However, it is still essential for plants as it aids the host in several important functions either in physiological or ecological effects. Plant secondary metabolites can be classified into four major classes, which are alkaloids, terpenoids, phenolic compounds, and sulphur-containing compounds. Plants use these phytochemicals as antimicrobial, attractants, repellents, and as deterrents against herbivores [1]. Azolla pinnata is an aquatic plant that has high potential content of secondary metabolites [2]. It is usually used for additional nutrition in feed for livestock [3] and natural fertilizer providers in paddy fields [4]. Not only that, but it is also known to have an environmental remediation effect on wastewater [5]. Thus, in order to explore more the potential of A.pinnata, a study on different extraction techniques and fertilizers were conducted to analyze the secondary metabolites obtained from A.pinnata.

\subsection{Material and Methods}

\subsection{Propagation of $A$. pinnata}

The fresh material of A. pinnata was collected from the Glasshouse \& Nursery Complex (GNC), IIUM Kuantan. The plant then propagated in the glasshouse under direct sunlight at room temperature. Dechlorinated tap water and chicken manure were used to maintain and propagate the plant.

\subsection{Application of fertilizer}

The chicken manure and $\mathrm{AB}$ fertilizer were used for the test. First, the fertilizer dissolved in dechlorinated tap water for five days. Then, A. pinnata was transferred to the media and left for seven days to grow.

\subsection{Collection and storing of plant sample}

The plant was harvested, washed with water and dried under sunlight for three days. Then, the samples were collected, packed in a zipped plastic bag, and stored in $-80^{\circ} \mathrm{C}$ refrigerator to be preserved before further use.

\subsection{Extraction Methods}

Two types of extraction methods used in this study are Soxhlet extraction and Supercritical Fluid Extraction (SFE). The extracts obtained from both methods were collected and kept safe before used for analysis.

\subsubsection{Extraction using Soxhlet method}

Following the standard method of Soxhlet extraction but with some alteration [6], the extractions were carried out by using a dried powdered sample for approximately 12 hours. 11 grams of the dried powdered sample was inserted into paper thimble and covered with cotton before extracted to ensure that the sample will not be flowing onto other apparatus. The round-bottom flask filled with $250 \mathrm{ml}$ of methanol was positioned on a heating mantle and heated not more than $64^{\circ} \mathrm{C}$. After the siphon arm became clear from the evaporations, the methanolic extract was collected. The extracts were then concentrated using a rotary evaporator. The concentrated extracts obtained were kept in a wrapped beaker and stored for further analysis.

\subsubsection{Supercritical Fluid Extraction (SFE) method}

Supercritical fluid extraction consists of a carbon dioxide pump, solvent pump, back pressure regulator, extractor vessel, pressure transmitter, and sample collector. $11 \mathrm{~g}$ of the dried powdered sample was loaded into an extraction vessel and was placed in a column oven. The extractions were performed at conditions near $3.5 \mathrm{MPa}, 60^{\circ} \mathrm{C}$ and $2 \mathrm{ml} / \mathrm{min}$ with $20 \%$ methanol for both extraction of A.pinnata with chicken manure and AB fertilizer [7]. The carbon dioxide will flow through a long tubular preheating coil for 4 minutes to ensure that it reaches the extraction temperature before contacting the sample in the extraction vessel. A back-pressure regulator is used to control the extraction pressure. A chiller was used to maintain the liquid state of the liquefied carbon dioxide at $-4^{\circ} \mathrm{C}$ before the extraction process began. After extraction began, separated components of the sample were collected in sample collector. The extracts were then concentrated using a rotary evaporator. The concentrated extracts obtained were kept in a wrapped beaker and stored for further analysis. 


\subsection{Analysis of Secondary Metabolites Using Gas Chromatography-Mass Spectrometer (Gc-Ms)}

The chemicals constituents of the yield extracted by Soxhlet and SFE techniques were analyzed to determine the secondary metabolites compounds using gas chromatography and mass spectrometer. A sample was desiccated first to ensure it is free from water, and a splitless-injector and reverse column were used in this analysis [8]. The samples mixtures were heated at $80^{\circ} \mathrm{C}$ for 30 minutes then $2 \mu \mathrm{L}$ of plant extracts were injected automatically by GCMS. Chromatogram reading appeared on screen, and the peaks were observed and analyzed in order to determine the total metabolic compounds on the plant extract.

\subsection{Results and Discussion}

\subsection{The effect of different fertilizers (Chicken manure and $A B$ fertilizer) on A.pinnata}

Figures 1,2, and 3 presented the result from the observation for week one, week three, and week five, respectively. In week one, both of the A.pinnata with $\mathrm{AB}$ fertilizer and chicken manure showing great condition. In week three, A.pinnata, with AB fertilizer, started to have yellowing leaves in some parts of the plant while A.pinnata with chicken manure remained the same. In week five, all of the A.pinnata with AB fertilizer had yellowing leaves while A.pinnata with chicken manure still remained the same. Based on the observation, A.pinnata growth in AB fertilizer slightly turned to decolouration, whereas A.pinnata with chicken manure fertilizer remained healthy. A.pinnata fertilized with chicken manure managed to survive and maintain healthy conditions throughout this test, while, on the other hand, A.pinnata fertilized with AB showed slight degradation on growth.

Figures below show the condition of A.pinnata by only fertilized one time for week one, week three, and week five.
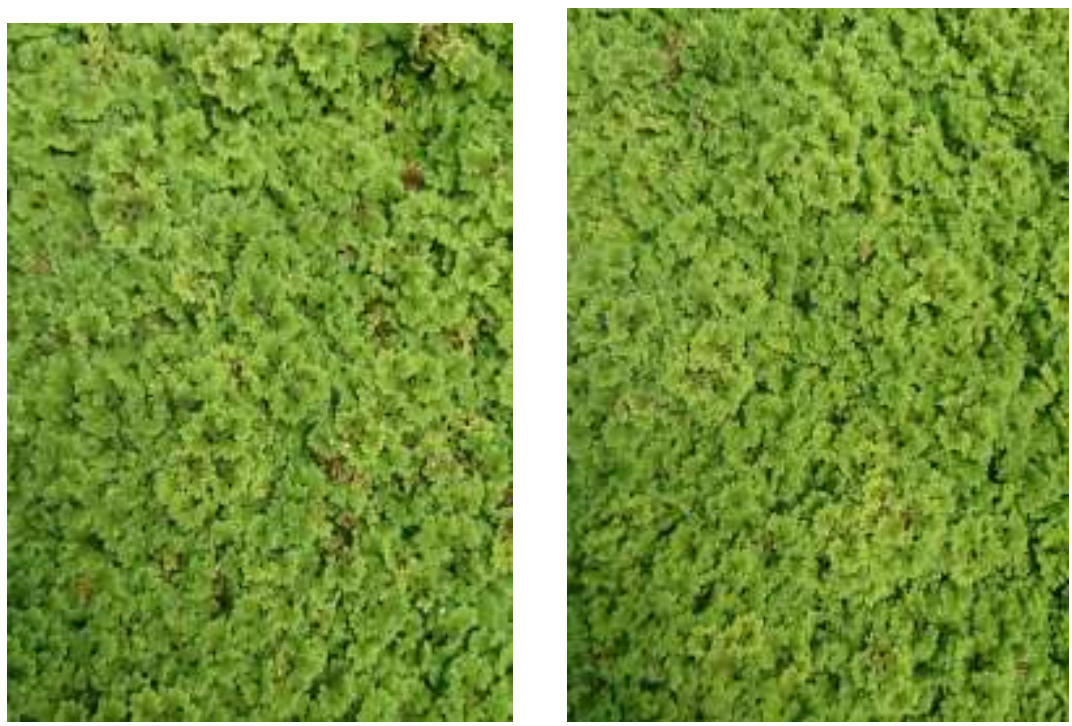

Figure 1: The condition of A.pinnata in week one, left (AB fertilizer) right (chicken manure)
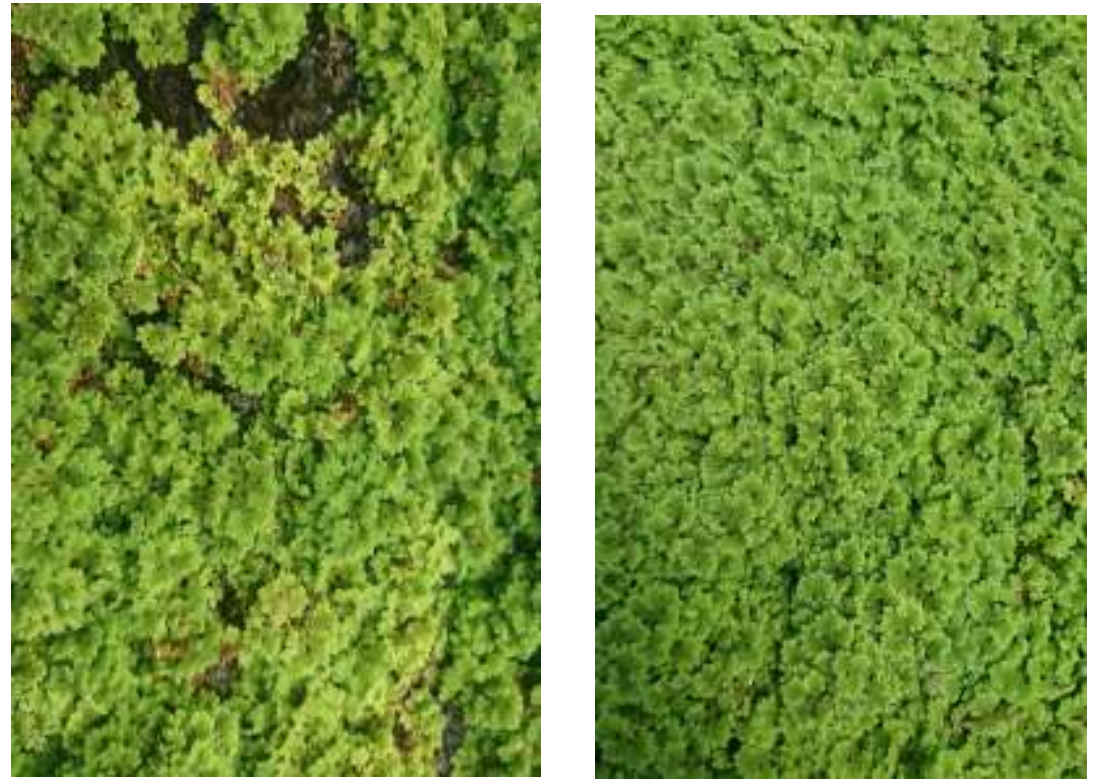

Figure 2: The condition of A.pinnata in week three, left (AB fertilizer) right (chicken manure) 

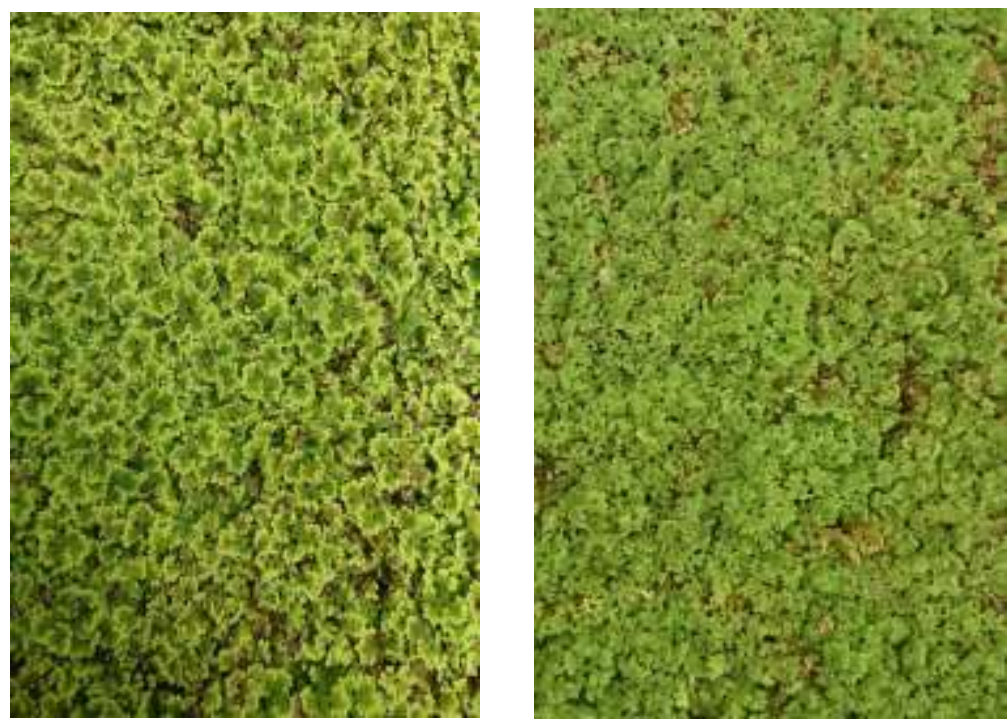

Figure 3: The condition of A.pinnata in week five, left ( $\mathrm{AB}$ fertilizer) right (chicken manure)

Granule fertilizer provided a slow release of nutrients. Thus, this helps in feeding crops for a longer period [9]. Chicken manure used in this study was in granule form, and this helped the A.pinnata to live healthily and throughout the five weeks test. On the other hand, the AB fertilizer used was liquid fertilizer, and the nutrition was released simultaneously and absorbed instantly by A.pinnata. The remaining nutrients decreased rapidly through time, and in the end, the nutrients depleted and lead to malnutrition of A.pinnata. The liquid fertilizer was also susceptible to volatilization; thus, it also caused the decrease of nutrient for the A.pinnata [10]. In this study, the A.pinnata that grew for one week were chosen for extraction because to obtain plant samples in optimum condition as well as avoiding decrease quality of plant samples before use.

\subsection{Total dry weight of A.pinnata obtained from different fertilizers}

The table below shows the dry weight of A.pinnata using two different fertilizers, chicken manure, and AB fertilizer.

Table 1: Dry weight of A.pinnata using different fertilizer

\begin{tabular}{ll}
\hline Type of fertilizer & Dry weight obtained (g) \\
\hline Chicken Manure & $71.4 \mathrm{~g}$ \\
AB fertilizer & $79.8 \mathrm{~g}$ \\
\hline
\end{tabular}

Table 1 shows the total dry weight of A.pinnata obtained after dried for three days. The result shows that the total dry weight of A.pinnata obtained from using AB fertilizer is higher compared to A.pinnata using chicken manure fertilizer. The difference between the total dry weights of A.pinnata was $8.4 \mathrm{~g}$ which is about $10.5 \%$ difference. Granules type fertilizer provided better growth [11]; however, from this test, AB fertilizer weighed more compared to chicken manure. This could be because of A.pinnata being an aquatic plant, so it can directly absorb nutrients from the liquid AB fertilizer through the water while floating [12]. Thus, having nutrients in complete liquid form causes the nutrient to be easily absorbed by A.pinnata. So, it is safe to say that AB fertilizer provides much more nutrients compared to chicken manure as it leads to better growth and provides a higher total weight.

\subsection{Total extracts of A.pinnata obtained from utilizing different fertilizers and extraction methods}

Tables 2 and 3 show the total weight obtained of A.pinnata and their mean using two different fertilizers.

Table 2: Total extracts weight obtained from different fertilizer and extraction method

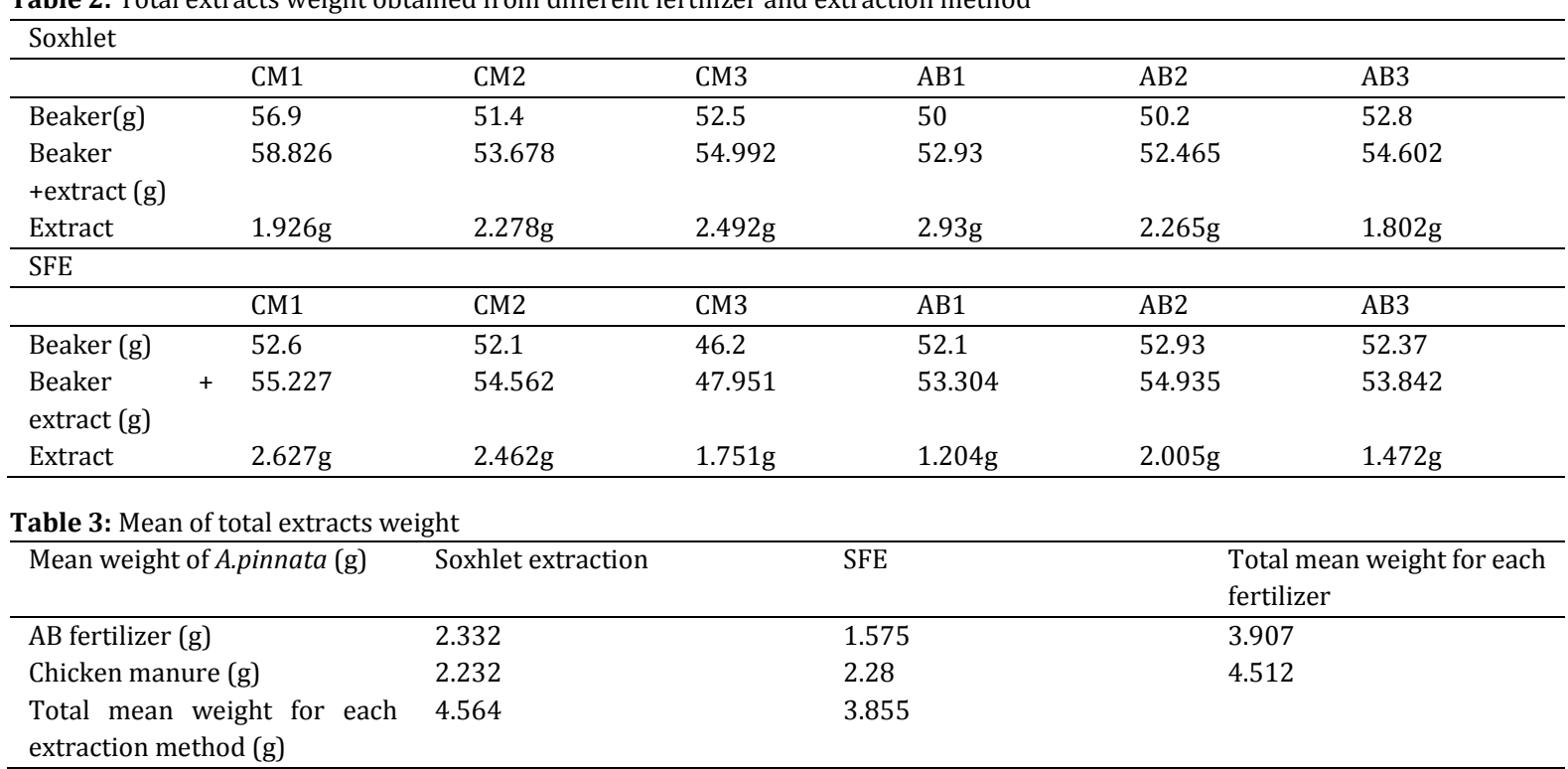

Tables 2 and 3 showed the result of the total extract obtained by using two different fertilizers and two different extraction methods. The extraction methods 
used were Soxhlet extraction and SFE. The result showed that the highest mean weight obtained for A.pinnata for this test is by using AB fertilizer with Soxhlet extraction. Different methods of extraction may produce different amounts of extract in the result [13] [14]. The amount of extract obtained highly depends on the capabilities of the extraction methods to extract the specific type of compounds [15]. In this study, the amount of extract produced from Soxhlet extraction and SFE was almost the same. Thus, this shows that different extraction methods produced different amounts of extracts; however, Soxhlet extraction and SFE produced almost the same amount of extracts.

3.4. Secondary metabolites obtained from A. pinnata through analysis using GC-MS

After obtaining the yield from both extraction methods and fertilizer, the samples were introduced to the GC-MS machine for further analysis. Figure 4 and Table 4 show the data collected and interpreted from GC-MS.

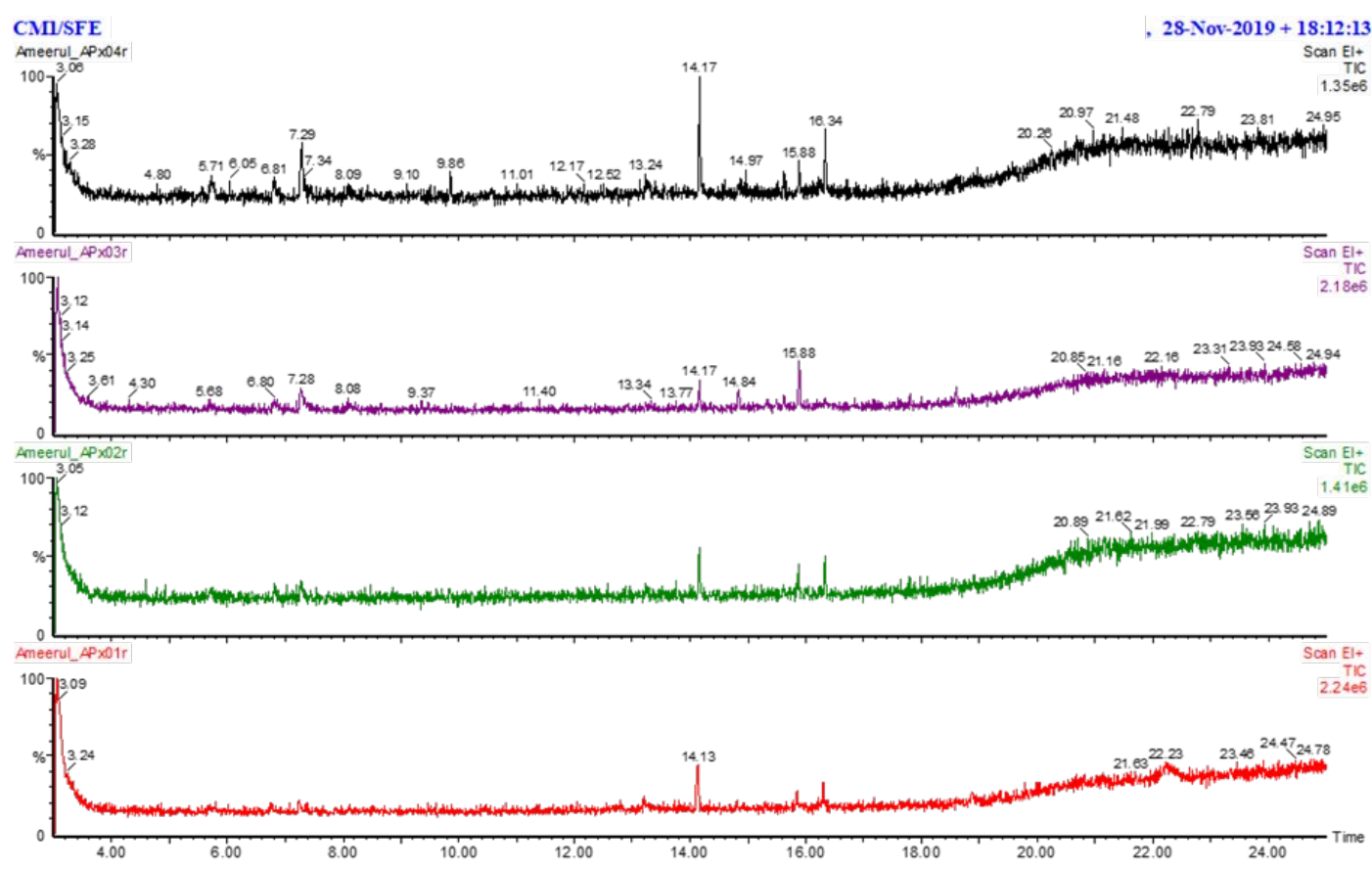

Figure 4: Chromatogram graph obtained from A.pinnata using GC-MS analysis (Black- using AB fertilizer and SFE, purple- using AB fertilizer and Soxhlet extraction, green- using chicken manure and SFE and red- using chicken manure and Soxhlet extraction).

Table 4: Interpreted data obtained from GC-MS analysis

\begin{tabular}{|c|c|c|c|c|c|c|c|c|c|c|}
\hline & & $\mathrm{AB} / \mathrm{SFE}$ & & $\mathrm{AB} / \mathrm{SOX}$ & & $\mathrm{CM} / \mathrm{SFE}$ & & $\mathrm{CM} / \mathrm{SOX}$ & & \\
\hline $\begin{array}{l}\text { Peak } \\
\text { No. }\end{array}$ & $\begin{array}{l}\text { Retention } \\
\text { Time }\end{array}$ & Area & $\%$ Area & Area & $\begin{array}{l}\% \\
\text { Area }\end{array}$ & Area & $\begin{array}{l}\% \\
\text { Area }\end{array}$ & Area & $\%$ Area & $\begin{array}{l}\text { Expected } \\
\text { Element }\end{array}$ \\
\hline 1 & 5.71 & 12250 & 9.04 & 1429 & 1.47 & 3831 & 5.00 & 3604 & 4.75 & Theamine \\
\hline 2 & 6.81 & 11763 & 8.68 & 11544 & 11.85 & 2620 & 3.42 & 3301 & 4.35 & Bioxirane \\
\hline 3 & 7.29 & 28252 & 20.84 & 20372 & 20.91 & 7652 & 9.98 & 8712 & 11.48 & Acetic acid \\
\hline 4 & 9.86 & 6533 & 4.82 & 3235 & 3.32 & 5370 & 7.01 & 2127 & 2.80 & $\begin{array}{l}9 \text { Methyl-1- } \\
\text { decene }\end{array}$ \\
\hline 5 & 13.24 & 5771 & 4.26 & 4859 & 4.99 & 10389 & 13.56 & 4176 & 5.50 & Glycerine \\
\hline 6 & 14.17 & 36709 & 27.08 & 15394 & 15.80 & 20368 & 26.58 & 26706 & 35.19 & $\begin{array}{l}\text { Dihydroxyacet } \\
\text { one }\end{array}$ \\
\hline 7 & 14.84 & 3561 & 2.63 & 7370 & 7.56 & 2067 & 2.70 & 2445 & 3.22 & Thymine \\
\hline 8 & 15.88 & 9288 & 6.85 & 20874 & 21.43 & 8009 & 10.45 & 8396 & 11.06 & Pyranone \\
\hline 9 & 16.34 & 15450 & 11.40 & 3034 & 3.11 & 11280 & 14.72 & 11203 & 14.76 & $\begin{array}{l}\text { 6-Fluoro-2- } \\
\text { trifluorometh } \\
\text { ylbenzoic acid, } \\
\text { 2-formyl-4,6- } \\
\text { dichloropheny } \\
\text { l ester }\end{array}$ \\
\hline 10 & 18.61 & 5982 & 4.41 & 9317 & 9.56 & 5049 & 6.59 & 5220 & 6.88 & Isoglutamine \\
\hline TOTAL & & 135559 & 100.00 & 97428 & $\begin{array}{l}100.0 \\
0\end{array}$ & 76635 & $\begin{array}{l}100.0 \\
0\end{array}$ & 75890 & 100.00 & \\
\hline
\end{tabular}

\section{AB- AB fertilizer}

CM- Chicken manure

SOX- Soxhlet extraction

SFE- Supercritical fluid extraction

Overall, A.pinnata with AB fertilizer contains higher total metabolites compared to A.pinnata with chicken manure. Theamine, 9 Methyl-1-decene, glycerine and 6-Fluoro-2-trifluoromethylbenzoic acid, 2-formyl-4,6-dichlorophenyl ester metabolites groups extracted better with SFE, while thymine, pyranone, and isoglutamine metabolites groups extracted better in Soxhlet extraction. Some of the metabolites, such as bioxirane, acetic acid, and dihydroxyacetone, 
compared to SFE. This also applies to both acetic acid and dihydroxyacetone. In a recent study, it was recorded that Soxhlet extraction is better in extracting alcohol-based compounds, whereas SFE is better in extracting phenolics and terpenes-based compounds [15]. Based on the result, the specific class of the compounds was difficult to identify but, can be observed that different extraction methods extracted different amount of secondary metabolites.

Different extraction methods will produce different amounts of total extracts, which contribute largely to the total amount of metabolites produced [13][14] However, the amounts of metabolites obtained from Soxhlet extraction and SFE are almost the same [15]. Each extraction used can result in different amounts of specific compounds obtained [16]. Different extraction methods can be chosen depending on the desired metabolites. In this test, no desired metabolites were being specifically targeted; only the overall amount and types of metabolites was being researched. For the fertilizers, AB fertilizer can be seen to have a large gap in the total amount of metabolites compared to chicken manure. Almost all the comparisons between these two resulted in A.pinnata with $\mathrm{AB}$ fertilizer to have a higher amount of metabolites compared to A.pinnata with chicken manure. Thus, this shows that $\mathrm{AB}$ fertilizer is better than chicken manure in improving the metabolites content in A.pinnata while SFE and Soxhlet extraction can be used depending on the desired metabolite but, for overall performance, SFE managed to extract more metabolites compared to Soxhlet extraction.

From all the metabolites from the result in (Table 4), glycerine showed the obvious differences from the whole metabolites detected from samples using chicken manure compared to AB fertilizer. However, it applies only to A.pinnata by using chicken manure with SFE. For A.pinnata that treated with chicken manure and extracted using soxhlet, a lower amount of glycerine was detected compared to the plant treated with AB fertilizer. There are no data recorded regarding chicken manure's improvement in the amount of glycerine content of A.pinnata. Thus, this may occur being caused by foreign substances produced from error in handling the extracted sample.

\subsection{Conclusion}

The application of different extraction methods led to different amounts of metabolites obtained from A.pinnata. Extraction by using SFE managed to gain higher overall amounts of secondary metabolites compared to Soxhlet extraction. Each of the extractions was able to obtain higher amounts of different particular metabolites. Different extraction methods affect the amount of total extraction obtained. All of the extraction methods that were used produced an almost similar amount of extraction because Soxhlet extraction and SFE were known to have abilities to extract almost similar amounts of total extracts. However, in this study, SFE produced more metabolites compared to Soxhlet extraction. Based on the study, fertilizers also play important roles in determining the amounts of secondary metabolites obtained. $A B$ fertilizer was found to be more successful than chicken manure in improving the amount of secondary metabolites in A.pinnata. Hence, it can be said that AB fertilizer is better than chicken manure in improving the content of secondary metabolites in A.pinnata.

\subsection{References}

[1] H. Zulkrnin, N. Shaida, N.N. Rozhan, N.A. Zulkfili, N. Yusoff, N. Raihan, I.H. Ishak, "Larvicidal effectiveness of Azolla pinnata against Aedes aegypti (Diptera: Culicidae) with its effects on larval morphology and visualization of behavioural response”, Journal of parasitology research, 2018.

[2] B. Nordiah, Z.M. Harah, B.J., Sidik, W.W. Hazma, "Azolla pinnata Growth Performance in Different Water Sources", Pakistan Journal of Biological Sciences, Vol. 15, No. 13, Pp. 621-628, 2012.

[3] B. Basak, M.A.H. Pramanik, M.S. Rahman, S.U. Tarafdar, B.C. Roy, "Azolla (Azolla pinnata) as a feed ingredient in broiler ration", International Journal of Poultry Science, Vol. 1, Pp. 29-34, 2002.

[4] A.K. Mishra, K.N. Mishra, "Use of Azolla pinnata as biofertilizer for the production of rice Pant-4 in Jaunpur district (UP), India", Plant Archives, Vol. 7, No. 1, Pp. 313-316, 2007

[5] U. Song, H. Park, E.J. Lee, "Ecological responses and remediation ability of water fern (Azolla japonica) to water pollution", Journal of Plant Biology, Vol. 55, No. 5, Pp. 381-389, 2012.

[6] T. Dhanani, S. Shah, N.A. Gajbhiye, S. Kumar, "Effect of extraction methods on yield, phytochemical constituents and antioxidant activity of Withania somnifera", Arabian Journal of Chemistry, Vol. 10, Pp. S1193-S1199, 2017.

[7] I. Subuki, A.N. Malck, H. Saidin, M.M. Pisar, "Optimization of supercritical extraction conditions of Senna alata and evaluation of biological activity", International Journal of Engineering \& Technology, Vol. 7, No. 3.11, Pp. 94-100, 2018.

[8] F. Orata, "Derivatization reactions and reagents for gas chromatography analysis. Advanced Gas Chromatography Progress in Agricultural", Biomedical and Industrial Applications, Pp. 83-108, 2012.

[9] T. Misselbrook, S. Bittman, C.M. d. S. Cordovil., B. Ress, S.B. Roger, J. Olesen, A. Vallejo, "Field application of organic and inorganic fertilizers and manure", Task Force on Reactive Nitrogen, 2019.

[10] R.L. Mahler, “Fertilizer Placement”, University of Idaho College of Agriculture, 2001.

[11] O.N. Adeniyan, A.O., Aluko, S.O. Olanipekun, "Effect of Combination of Soil Granular NPK and Foliar Liquid Fertilizer on Nutrients Uptake and Maize Yield", Journal of Experimental Agriculture International, Pp. 1-8, 2016.

[12] U. Kremser, E. Schnug, "Impact of fertilizers on aquatic ecosystems and protection of water bodies from mineral nutrients", Landbauforschung Volkenrode, Vol. 52, No. 2, Pp. 81-90, 2002.

[13] Q.W. Zhang, L.G. Lin, W.C. Ye, "Techniques for extraction and isolation of natural products: A comprehensive review", Chinese medicine, Vol. 13, No. 1, 2018.

[14] B. Trusheva, D. Trunkova, V. Bankova, "Different extraction methods of biologically active components from propolis: a preliminary study", Chemistry Central Journal, Vol. 1, No. 1, Pp. 13, 2007.

[15] N. Herzi, J. Boujila, S. Camy, M. Romdhane, J.S. Condoret, "Comparison of different methods for extraction from Tetraclinis articulata: Yield, chemical composition and antioxidant activity", Food chemistry, Vol. 141, No. 4, Pp. 3537-3545, 2013.

[16] E. Aspé, K. Fernández, "The effect of different extraction techniques on extraction yield, total phenolic, and anti-radical capacity of extracts from Pinus radiata Bark", Industrial Crops and Products, Vol. 34, No. 1, Pp. 838-844, 2011. 